\title{
Pengenalan Gedung Kampus Universitas Sam Ratulangi Dengan Pemanfaatan Augmented Reality Dan Layanan Berbasis Lokasi
}

\author{
Tri Wenda Ginting ${ }^{1)}$, Virginia Tulenan ${ }^{2)}$ Hans Wowor ${ }^{3)}$ \\ 1,2,3 Program Studi Teknik Informatika, Fakultas Teknik, Universitas Sam Ratulangi \\ E-mail : triginting120216008@ gmail.com ${ }^{1)}$, virginia.tulenan@unsrat.ac.id ${ }^{2}$ hanswowor@unsrat.ac.id ${ }^{3)}$,
}

\begin{abstract}
Abstrak - Universitas Sam Ratulangi merupakan salah satu universitas tertua di Sulawesi Utara, dan juga merupakan salah satu himpunan komunitas akademik terbesar di kawasan timur Indonesia. Setiap tahunnya, UNSRAT menggelar penerimaan calon mahasiswa baru yang multikultural lewat berbagai jalur. Biasanya, calon mahasiswa baru baik yang dari dalam maupun luar Sulawesi Utara banyak yang kebingungan dalam mengetahui lokasi gedung kampus dan layanan-layanan yang disediakan di gedung tersebut. Oleh karena itu dibuatlah aplikasi pengenalan gedung kampus Universitas Sam Ratulangi dengan pemanfaatan augmented reality dan layanan berbasis lokasi. Metode pengembangan sistem yaitu metode Rapid Application Development (RAD) dengan bahasa pemodelan terpadu (UML) sebagai desain sistem.

Hasil dari penelitian ini adalah sebuah aplikasi pengenalan gedung kampus Universitas Sam Ratulangi dengan pemanfaatan augmented reality dan layanan berbasis lokasi pada smartphone bersistem operasi android. Terdapat empat menu utama pada aplikasi tersebut, yaitu menu AR, LBS, Tentang, dan Keluar.

Aplikasi ini dapat mempermudah untuk mengetahui lokasi gedung kampus dan memberikan informasi dibidang akademik, bidang kemahasiswaan, bidang umum, dan bidang keuangan dan kepegawaian mengenai layanan apa saja yang disediakaan.
\end{abstract}

Kata Kunci : Rapid Application Development, UML, Android.

\section{Pendahuluan}

Universitas Sam Ratulangi (UNSRAT) merupakan salah satu universitas tertua di Sulawesi Utara, dan juga merupakan salah satu himpunan komunitas akademik terbesar di kawasan timur Indonesia (www.unsrat.ac.id, diakses pada 6 Februari 2016).

Dewasa ini, semakin banyak bermunculan teknologi-teknologi baru di bidang Teknologi Informasi (TI). Teknologi-teknologi tersebut semakin berkembang dengan sangat pesat. Salah satu teknologi yang saat ini sedang berkembang pesat adalah Augmented Reality (AR).

$\mathrm{AR}$ atau dalam bahasa Indonesia sering disebut

dengan Realitas Tertambah adalah teknologi yang menggabungkan benda maya dua dimensi maupun tiga dimensi kedalam sebuah lingkungan nyata lalu memproyeksikan benda-benda maya tersebut dalam realtime (Ronald T. Azuma, 1997).

Bagi calon mahasiswa baru dan mahasiswa baru yang diterima di UNSRAT beserta dengan masyarakat, informasi mengenai gedung kampus merupakan suatu hal yang sangat penting untuk diketahui. Biasanya, calon mahasiswa baru baik yang dari dalam maupun luar Sulawesi Utara banyak yang kebingungan dalam mengetahui lokasi gedung dan layanan-layanan yang disediakan di gedung tersebut dan hal tersebut juga berdasarkan dari pengalaman penulis. Mahasiswa baru mengetahui lokasi gedung kampus pada saat kegiatan Pengenalan Kehidupan Kampus Mahasiswa Baru (PK2MB). Bahkan, mahasiswa yang sudah terbilang cukup lama kuliah di UNSRAT masih kurang tahu layananlayanan yang disediakan di fakultas. Informasi bentuk pelayanan tersebut diambil dari lima fakultas dan UPT. TIK. Kelima fakultas tersebut adalah Fakultas Teknik, Fakultas Matematika dan Ilmu Pengetahuan Alam, Fakultas Pertanian, Fakultas Peternakan dan Fakultas Ilmu Budaya.

Dengan demikian, perlu adanya alternatif media untuk memudahkan mengetahui nama, dan layananlayanan apa saja yang tersedia pada gedung kampus. Dengan pemanfaatan teknologi AR yang dapat memvisualisasikan informasi secara interaktif, maka penulis akan membuat sebuah Aplikasi Pengenalan Gedung Kampus Universitas Sam Ratulangi dengan Pemanfaatan Augmented Reality dan Layanan Berbasis Lokasi. Dimana aplikasi dapat berjalan di platform berbasis android yang telah mendukung adanya GPS, kamera, compass, dan acceloremeter.

Dengan aplikasi tersebut maka dapat membantu masyarakat dan mahasiswa dalam mengetahui lokasi gedung kampus dan layanan-layanan yang disediakan. Selain itu aplikasi ini juga dapat menjadi media alternatif untuk digunakan oleh instansi UNSRAT sebagai penyebaran informasi.

\section{LANDASAN TEORI}

\section{A. Augmented Reality}

AR dapat diaplikasikan untuk semua indera, seperti pendengaran, sentuhan, dan penciuman. AR telah banyak digunakan dalam berbagai bidang, seperti bidang kesehatan, militer, industri manufaktur, selain itu AR juga telah diaplikasikan dalam perangkat-perangkat yang 
digunakan oleh banyak orang, seperti pada telepon genggam.

AR berfungsi untuk menambahkan informasi dan makna pada sebuah objek nyata atau tempat. Dibutuhkan objek nyata atau ruang sebagai dasar dan menggabungkan teknologi yang menambahkan data kontekstual untuk memperdalam pemahaman seseorang dari subjek.

Ada dua metode yang digunakan pada AR yaitu

marker based tracking dan markerless.

\section{Marker Based Tracking}

Marker based tracking merupakan AR yang menggunakan marker atau penanda objek 2D yang memiliki suatu pola yang akan dibaca komputer melalui media webcam atau kamera yang tersambung dengan komputer. Marker based tracking biasanya merupakan ilustrasi hitam dan putih persegi dengan batas hitam tebal dan latar belakang putih.

2. Markerless

Metode markerless merupakan metode yang mana pengguna tidak perlu lagi mencetak sebuah marker untuk menampilkan elemen-elemen digital. Dalam hal ini, marker yang dikenali berbentuk posisi perangkat, arah, maupun lokasi.

\section{B. Mixare}

Mixare (Mix Augmented Reality Engine) adalah open source augmented reality browser yang diterbitkan dibawah GPLv3. Mixare tersedia untuk Android dan iPhone 3GS dan diatasnya. Mixare bekerja sebagai aplikasi yang sangat otonom dan tersedia untuk pengembangan dari implementasi sendiri.

Ada beberapa cara dalam menggunakan mixare, yaitu :

1. Mixare adalah sebuah aplikasi otonom yang menampilkan POI Wikipedia terhadap lingkungannya. Mixare dijalankan di perangkat mobile secara langsung.

2. Mixare dapat diakses oleh link pada situs HTML, dimana sumber data ditransfer ke aplikasi.

3. Mixare dapat diakses oleh launcher-app kita sendiri, data source ditransfer ke aplikasi yang kita buat.

4. Mixare secara bebas di upgrade dan bahkan dapat dimodifikasi ke aplikasi individu.

\section{Layanan Berbasis Lokasi}

Layanan Berbasis Lokasi atau Location Based Service adalah layanan pada sebuah mobile device yang bergantung pada lokasi dari device. Menurut Purbojati dalam Iqbal.M (2013), bahwa dengan menggunakan Location Based Service, perangkat akan menentukan lokasinya, dan informasi ini digunakan untuk mendapatkan informasi berguna lainnya untuk user.

LBS dikelompokkan kedalam 3 jenis, antara lain :

1. Local information,

Memungkinkan pengguna untuk mencari layanan di sekitar mereka.

2. Traffic and tracking information,

Berfokus kepada pelacakan aset atau manusia

3. General services.

Tidak menyediakan informasi ke pengguna, namun menggunakan data lokasi pengguna. Contohnya layanan emergency.

Terdapat 2 unsur utama LBS, yaitu :

1. Location Manager (API Maps),

Location Manager (API Maps) menyediakan perangkat bagi sumber atau source untuk LBS, Application Programming Interface (API) Maps menyediakan fasilitas untuk menampilkan atau memanipulai peta.

2. Location Providers (API Location).

Location Providers (API Location) menyediakan teknologi pencarian lokasi yang digunakan oleh perangkat. API Location yang berhubungan dengan data GPS (Global Positioning System) dan data lokasi real-time.

\section{Antarmuka Pengguna}

Antarmuka merupakan media komunikasi pengguna saat akan berinteraksi dengan sistem (Sabariah, 2009). Oleh karena itu agar proses interaksi pengguna dengan sistem berjalan dengan baik maka perlu diketahui terlebih dahulu sejauhmana performansi karakteristik pengguna antarmuka, sehingga antarmuka yang dihasilkan dapat dengan mudah dipelajari, mudah dan nyaman pada saat digunakan. Perancangan antarmuka pengguna merupakan suatu proses yang kompleks, hal ini didasari karena antarmuka pengguna merupakan bagian dari sistem yang akan dikendalikan oleh pengguna dan merupakan tahap persiapan untuk rancang bangun implementasi.

\section{E. Metode Rapid Application Development}

metode Rapid Application Development (RAD) atau rapid prototyping yaitu metode yang menekankan pada siklus pembangunan pendek, singkat, dan cepat. Ada tiga fase daalam RAD yang melibatkan penganalisis dan pengguna dalam tahap penilaian, perancangan, dan penerapan. Adapun ketiga fase tersebut adalah requirements planning (perencanaan syarat-syarat), RAD Design workshop (workshop desain RAD), dan implementation (implementasi) (Kendall \& Kendall, 2010). Tahapan metode RAD dapat dilihat pada gambar 1 .

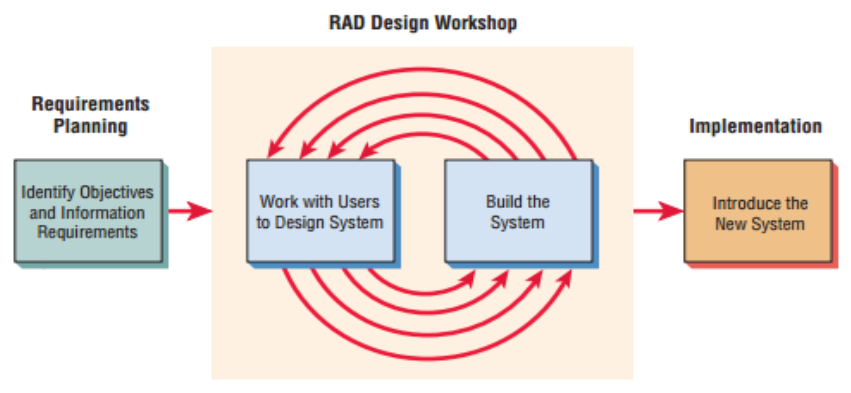

Gambar 1. Metode RAD

(Kendall, J.E. \& Kendall, K.E,2010)

\section{Requirement Planning}

Dalam fase ini, pengguna dan penganalisis bertemu untuk mengidentifikasikan tujuan-tujuan aplikasi atau sistem serta untuk megidentifikasikan syarat-syarat informasi yang ditimbulkan dari tujuan-tujuan tersebut.

2. Design Workshop

Fase ini adalah fase untuk merancang dan memperbaiki 
yang bisa digambarkan sebagai workshop. Penganalisis dan dan pemrogram dapat bekerja membangun dan menunjukkan representasi visual desain dan pola kerja kepada pengguna.

\section{Implementation}

Pada fase implementasi ini, penganalisis bekerja dengan para pengguna secara intens selama workshop dan merancang aspek-aspek bisnis dan nonteknis perusahaan. Segera setelah aspek-aspek ini disetujui dan sistem-sistem dibangun dan disaring, sistem-sistem baru atau bagian dari sistem diujicoba dan kemudian diperkenalkan kepada organisasi.

\section{METODELOGI PENELITIAN}

\section{A. Tempat Penelitian}

Penelitian dilaksanakan di UPT. TIK dan lima fakultas di Universitas Sam Ratulangi sebagai sample penelitian. Lima fakultas tersebut adalah Fakultas Teknik, Fakultas Matematika dan Ilmu Pengetahuan Alam, Fakultas Pertanian, Fakultas Peternakan, dan Fakultas Ilmu Budaya. Penelitian dari lima fakultas tersebut dilaksanakan di bidang akademik, bidang umum, bidang kemahasiswaan, bidang keuangan dan kepegawaian.

\section{B. Analisis Kebutuhan Sistem Hardware dan Software \\ 1. Hardware}

a. Satu perangkat laptop dengan spesifikasi : Sistem operasi Windows 8.1, Processor Intel(R) Core (TM) i3-4030U CPU @ 1.90GHz 1.90GHz, System type 64-bit Operating System, x64-based processor.

b. Dua perangkat handphone dengan sistem operasi android.

1. Versi hardware Smartfren Andromax AD687G.v1.00.

2. Versi hardware Sony C1505

c. Printer Canon IP1980

d. Alat tulis menulis

2. Software

a. Android Studio, berfungsi sebagai script editor.

b. Google Chrome, berfungsi sebagai web browser.

c. Photoshop, berfungsi sebagai pengeditan gambar.

d. Microsoft Word 2010, berfungsi sebagai pembuatan dokumen.

\section{Requirements Planning}

Berdasarkan metode RAD pada tahap I yaitu perencanaan syarat-syarat, peneliti melakukan pengumpulan data yang digunakan dalam penelitian ini adalah :

1. Studi Pustaka

Penulis melakukan studi pustaka untuk menghimpun informasi yang relevan dengan topik yang sedang diteliti. Informasi tersebut diperoleh dari buku-buku, jurnal-jurnal, dan situs resmi dari internet.

2. Wawancara

Penulis melakukan wawancara di UPT. TIK, dan lima fakultas sebagai sample di setiap bidang kemahasiswaan, bidang umum, bidang, keuangan dan kepegawaian, dan bidang akademik.

3. Kuesioner

Penulis menyebarkan kuesioner ke beberapa mahasiswa
UNSRAT pada tahap pra developing dan pasca depeloping. 4. Observasi

Penulis mengadakan tinjauan secara langsung ke objek yang diteliti. Observasi dilakukan di kampus UNSRAT dengan mengambil foto setiap gedung kampus.

\section{Design Workshop}

Berdasarkan metode RAD pada tahap II, yaitu design workshop, maka peneliti membuat user interface dari aplikasi yang akan dibangun dan membuat perancangan UML sebagai desain sistem.

1. Perancangan User Interface

\section{a. Icon Aplikasi}

Gambar 2 merupakan rancangan icon aplikasi yang berfungsi sebagai gambar atau logo kecil yang menandakan aplikasi

\section{Icon \\ Aplikasi}

Gambar 2. Rancangan Icon Aplikasi

b. Splash Screen

Gambar 3 merupakan rancangan splash screen aplikasi yang berfungsi untuk menampilkan tampilan sebelum masuk ke menu utama.

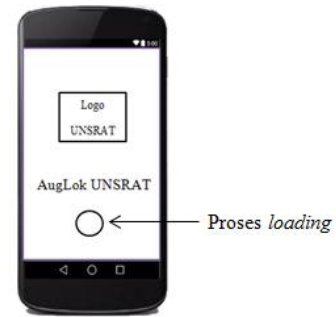

Gambar 3. Rancangan Splash Screen

c. Menu Utama

Gambar 4 merupakan rancangan tampilan menu utama yang terdiri dari empat menu, yaitu menu AR, LBS, Tentang, dan Keluar.

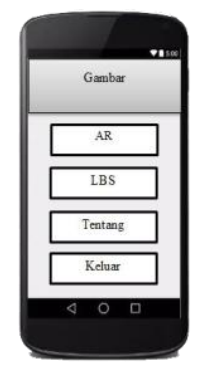

Gambar 4. Rancangan Menu Utama

2. Perancangan UML

a. Use Case Diagram

Terdapat 4 menu utama yaitu, AR, LBS, Tentang dan Keluar. 


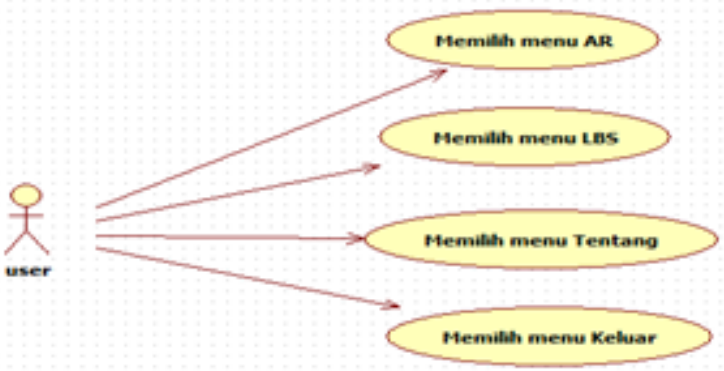

Gambar 5. Use Case Diagram

b. Activity Diagram

1. Activity Diagram AR

Ketika memilih menu AR sistem akan menampilkan nama fakultas beserta jarak dari posisi pengguna dengan fakultas tersebut. Ketika diklik, maka akan ditampilkan panorama gedung kampus.

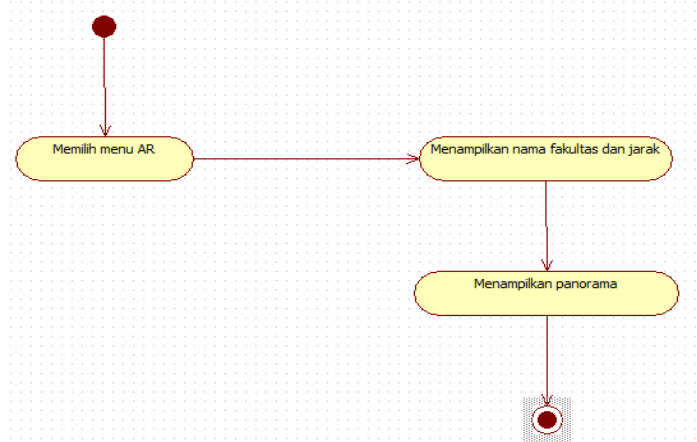

Gambar 6. Activity Diagram AR

\section{Activity Digram LBS}

Ketika memilih menu LBS, maka akan ditampilkan peta lokasi kampus yang ditandai dengan logo UNSRAT. Ketika diklik logo tersebut, maka akan menampilkan informasi layanan yang disediakan dibidang akademik, umum, kemahasiswaan, dan keuangan dan kepegawaian beserta dengan foto-foto gedung kampus.

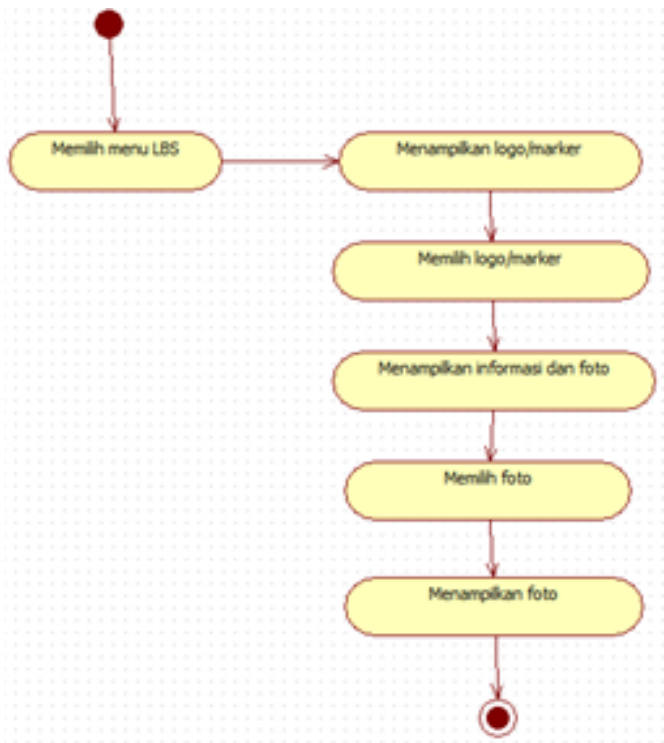

Gambar 7. Activity Diagram LBS
3. Activity Tentang

Ketika memilih menu Tentang maka akan ditampilkan informasi pembuat aplikasi.

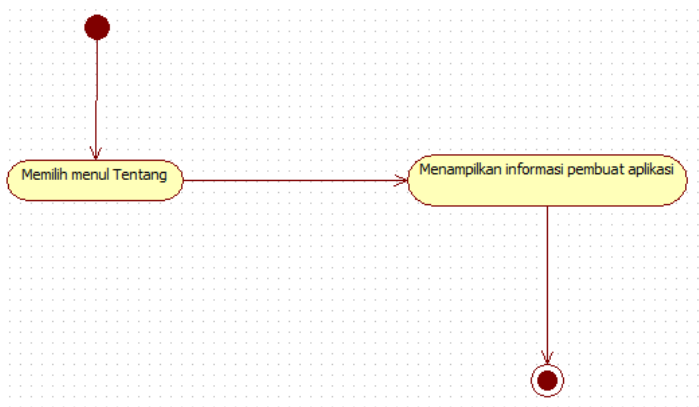

Gambar 8. Activity Diagram Tentang

4. Activity Keluar

Ketika memilih menu keluar, maka akan ditampilkan notifikasi untuk keluar.

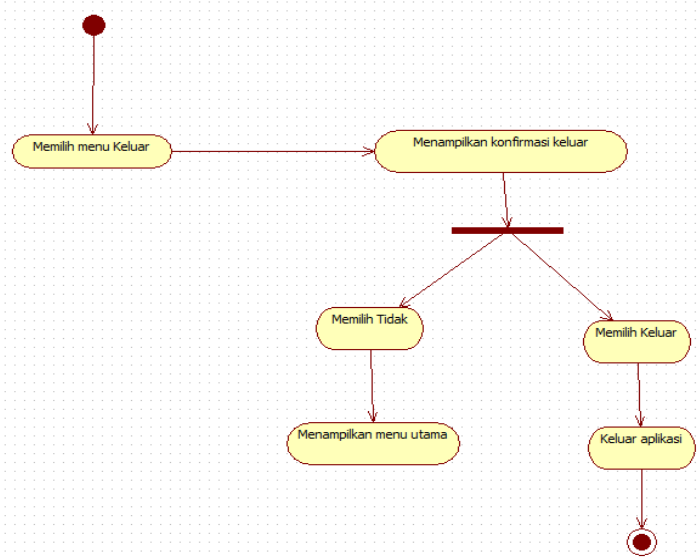

Gambar 9. Activity Diagram Tentang

\section{HASIL DAN PEMBAHASAN}

A. Hasil

1. Icon Aplikasi

Gambar 10 merupakan tampilan icon aplikasi pada smartphone android. Icon aplikasi ini berfungsi sebagai logo kecil penanda aplikasi.

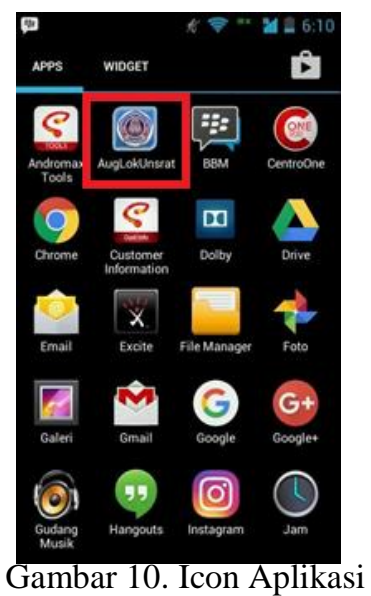


2. Splash Screen

Gambar 11 merupakan tampilan splash screen pada smartphone android. Splash screen ini berfungi untuk menampilkan tampilan proses loading sebelum masuk ke menu utama.

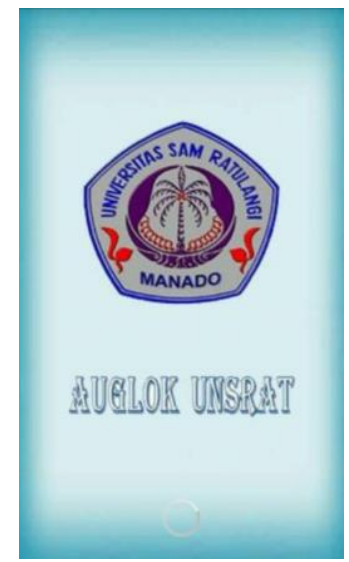

Gambar 11. Splash Screen

3. Menu Utama

Gambar 12 merupakan tampilan menu utama. Menu utama terdiri dari empat menu yaitu menu AR, LBS, Tentang, dan Keluar.

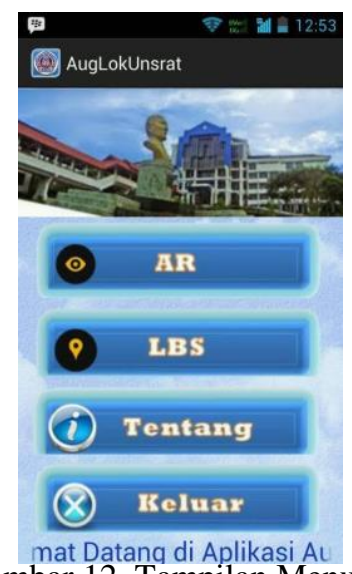

Gambar 12. Tampilan Menu Utama

\section{Tampilan AR}

Gambar 13 merupakan tampilan AR ketika Menu AR diklik dan pengguna mengarahkan smartphone android ke arah tertentu maka akan menampilkan nama lokasi dan jarak dari pengguna ke lokasi tersebut.

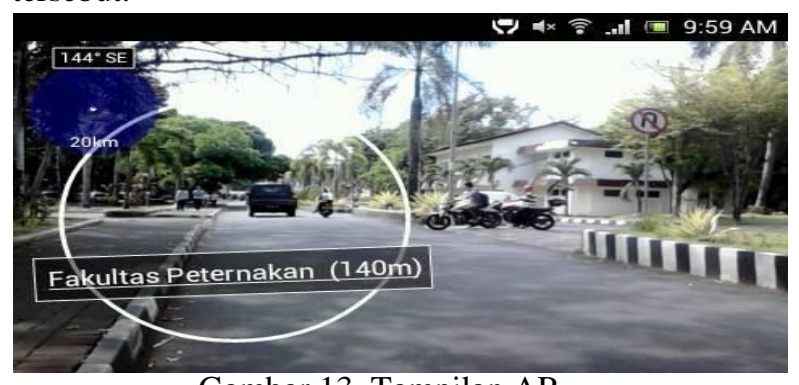

Gambar 13. Tampilan AR

Gambar 14 merupakan tampilan panorama gedung kampus ketika nama lokasi pada AR di klik.

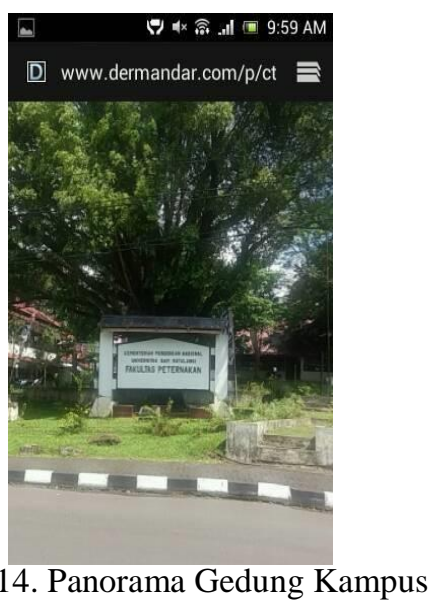

5. Tampilan LBS

Gambar 15 merupakan tampilan LBS yang menampilkan peta lokasi gedung kampus.

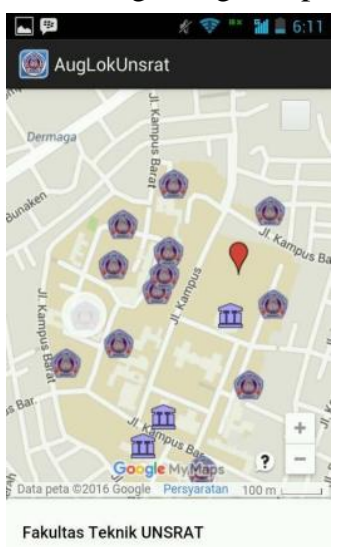

Gambar 15. Peta Lokasi Gedung Kampus

Apabila pengguna mengklik penanda lokasi pada peta tersebut maka akan menampilkan ditampilkan informasi layanan yang disediakan di bidang akademik, bidang kemahasiswaan, bidang keuangan dan kepegawaian, dan bidang umum.

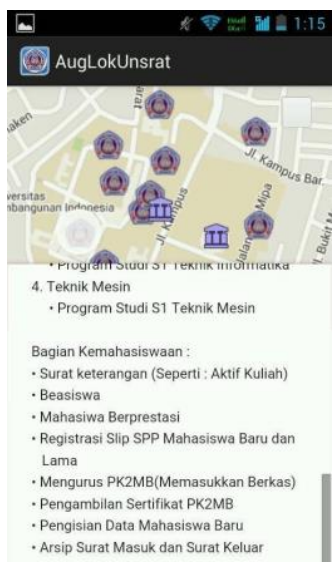

Gambar 16. Informasi Bentuk Layanan

Pada bagian akhir informasi layanan yang disediakan, terdapat foto-foto gedung kampus. Ketika foto diklik maka akan menampilkan slider 
foto-foto gedung kampus.

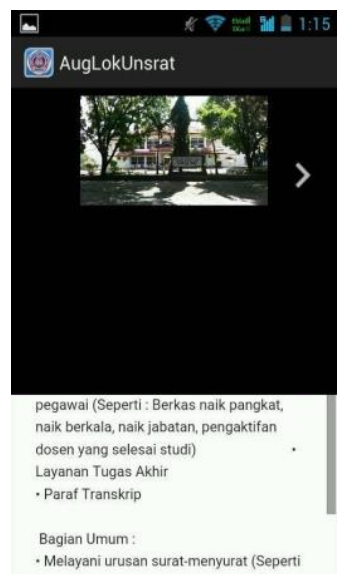

Gambar 17. Slider Foto Gedung Kampus

6. Tampilan Tentang

Gambar 18 merupakan tampilan Tentang yang berisi informasi pembuat aplikasi.

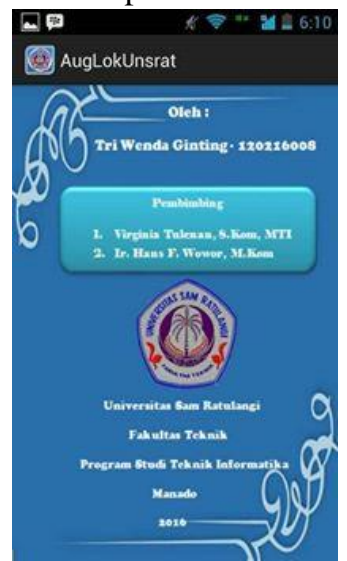

Gambar 18. Tampilan Tentang

7. Tampilan Notifikasi Keluar

Apabila memilih button keluar pada menu utama, maka akan muncul toast. Toast merupakan pesan text yang ditampilkan untuk memberikan informasi. Pesan toast tersebut adalah untuk menekan tombol back pada smartphone android untuk keluar dari aplikasi.

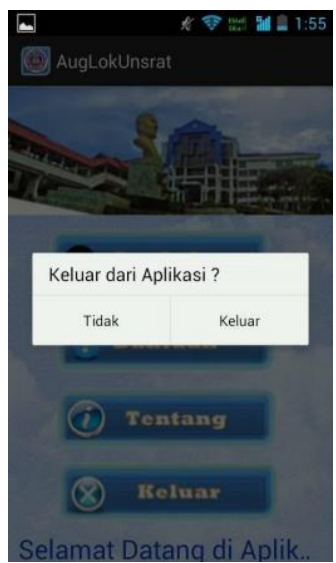

Gambar 19. Tampilan Notifikasi Keluar

\section{B. Pembahasan}

Dalam pembuatan aplikasi, peneliti menggunakan metode RAD sebagai pengembangan sistem. Metode RAD terdiri dari tiga tahapan, yaitu tahap perencanaan syaratsyarat, tahap workshop design, dan tahap impementasi.

Pada tahap perencanaan syarat-syarat, awalnya penulis mengalami kesulitan dalam pengambilan data karena tidak menggunakan surat penelitian dari program studi. Untuk mengatasi masalah tersebut, penulis akhirnya membuat surat penelitian untuk pengambilan data.

Pada tahap perancangan, peneliti berusaha membuat tampilan user interface yang user friendly. Pada tahap perancangan ini juga, tidak ada masalah yang dihadapi, karena pada tahap ini hanya membuat rancangan user interface. Pembuatan user interface ini juga dibicarakan dengan pengguna. Dimana pengguna aplikasi tersebut adalah mahasiswa.

Pada tahap implementasi, penulis menggunakan algoritma untuk membantu proses coding. Penulis menggunakan android studio untuk pembuatan aplikasi. Pada pembuatan aplikasi, hal yang perlu diperhatikan bahwa gambar harus berformat PNG atau JPEG. Kapasitas gambar tersebut tidak dibatasi, namun sebaiknya menggunakan resolusi yang baik untuk mendapatkan hasil yang maksimal. Dengan menggunakan android studio, penulis mendapat beberapa kemudahan sebagai berikut :

1. Android Studio dilengkapi dengan tampilan yang multi screen, dimana seorang developer dapat menulis kode-kode tertentu disatu sisi dan melihat tampilan hasilnya disisi lain.

2. Android Studio dilengkapi dengan Code Templates dan Github integration yang memudahkan developer android dalam mengembangkan aplikasi

Selain kemudahan, peneliti juga mendapatkan beberapa kendala sebagai berikut :

1. Android Studio terlalu banyak memakan memori saat dijalankan. Oleh karena itu, peneliti masih sering mengalami lag saat menggunakan Android Studio. Untuk mengatasi masalah tersebut peneliti menutup aplikasi yang tidak diperlukan agar tidak berjalan secara bersamaan. Dari hal tersebut, maka android studio dapat dijalankan dengan ringan.

2. Emulator pada android studio sering kali berjalan lambat, bahkan tidak bisa dijalankan. Untuk mengatasi masalah tersebut maka peneliti tidak menggunakan emulator, melainkan langsung dijalankan di smartphone android. Dengan emulator, aplikasi dapat dijalankan tanpa harus dicopy ke smartphone android, sedangkan apabila dijalankan di smartphone android file apk nya harus dicopy terlebih dahulu.

\section{Penutup}

\section{A. Kesimpulan}

1. Telah dihasilkan aplikasi pengenalan gedung kampus Universitas Sam Ratulangi dengan Pemanfaatan Augmented Reality dan Layanan Berbasis Lokasi dengan berbasis android.

2. Android Studio dengan bahasa pemrograman Java dapat membuat aplikasi android. 


\section{B. Saran}

Untuk menyempurnakan aplikasi yang telah dibuat ini, agar dapat lebih baik lagi dan dapat digunakan lebih efisien maka perlu dilakukan pengembangan lebih lanjut dengan menambahkan fitur-fitur yang ada dalam aplikasi.

\section{DAFTAR PUSTAKA}

[1] Abdur Rahman, Rancang Bangun Aplikasi Informasi Universitas Bengkulu Sebagai Panduan Pengenalan Kampus Menggunakan Metode Markerless Augmented Reality Berbasis Android, Program Studi Teknik Informatika, Fakultas Teknik, Universitas Bengkulu, 2014.

[2] Andika Satya Pratama, Khoerul Anwar, Aplikasi Penunjuk Arah Lokasi Kampus Stimata Menggunakan Teknologi Augmented Reality, Program Studi Teknik Informatika, STMIK PPKIA Pradnya Paramita Malang.

[3] Azuma, Ronald T. 1997. "A Survey of Augmented Reality". Presence: Teleoperators and Virtual Environments 6 (4): 355-385.

[4] Dea Angga Wisesa, "Pengembangan Media "DITAQU" Berbasis Android untuk Peserta Didik Difabel Netra Di TPA LB A Yaketunis Yogyakarta, Universitas Islam Negeri Sunan Kalijaga Yogyakarta, 2015.

[5] Julia Purnama Sari, Aan Erlansari, Rancang Bangun Aplikasi Layanan Berbasis Lokasi Dengan Penerapan Augmented Reality Menggunakan Metode Markerless Berbasis Android (Studi Kasus : Pencarian Perangkat Daerah Kota Bengkulu), Program Studi Teknik Infomatika, Fakultas Teknik, Universitas Bengkulu, Vol. 2, No. 2, November 2014.

[6] Kenneth E. Kendall, Julie E. Kendall, 2010, Analisis dan Perancangan Sistem, Jakarta, PT Indeks.

[7] Mira Kania Sabariah. Implikasi Performansi Profile Pengguna Terhadap Perancangan Antarmuka Perangkat Lunak, Universitas Komputer Indonesia, Vol. 7, No.1

[8] M. Iqbal, Aplikasi Travel Booklet Menggunakan Teknologi Augmented Reality Dan Location Based Service Berbasis Windows Phone. Universitas Komputer Indonesia, Bandung, 2013.

[9] Roger S. Pressman, Ph. D, Rekayasa Perangkat Lunak Pendekatan Praktisi (Buku Satu), Andi, Yogyakarta.

[10] Situs Resmi UNSRAT : www.unsrat.ac.id. Diakses pada tanggal 6 Februari 2016.

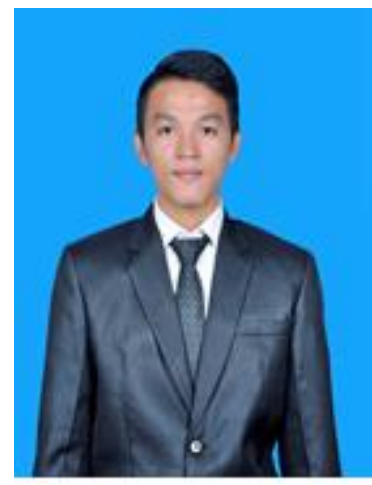

Sekilas dari penulis
dengan nama Tri Wenda
Ginting, anak ke-tiga dari
empat bersaudara. Lahir di
Kuta Buluh, Kabupaten Dairi,
Sumater Utara, pada tanggal 7
Agustus 1993. Dengan alamat
tempat tinggal sekarang di
Griya Sea Lestari 3, Manado.
Sekolah pertama tempat
belajar adalah SD N 030437

Kuta Buluh. Kemudian melanjutkan pendidikan ke SMP N 1 Tanah Pinem, dan melanjutkan pendidikan ke SMA N 1 Tanah Pinem. Pada tahun 2012, Penulis melanjutkan studi di Fakultas Teknik, Jurusan Elektro, Program Studi Informatika, Universitas Sam Ratulangi Manado. Kemudian pada tahun 2015 bulan Agustus penulis membuat skripsi demi memenuhi syarat Sarjana (S1) dengan penelitian berjudul "Pengenalan Gedung Kampus Universitas Sam Ratulangi dengan Pemanfaatan Augmented Reality dan Layanan Berbasis Lokasi" dengan pembimbing I oleh Virginia Tulenan, S.Kom,MTI dan pembimbing II oleh Ir. Hans F. Wowor, M.kom. Sehingga pada tanggal 29 September 2016 penulis resmi lulus di Teknik Informatika Universitas Sam Ratulangi dan menyandang gelar sebagai Sarjana Komputer. 